\title{
Análise de rótulos de suplementos alimentares em aulas de Química: uma atividade de ensino de CTS
}

\author{
Amanda Torres Vieira da Costa*, Jorge Cardoso Messeder**
}

\section{Resumo}

Este trabalho apresenta uma atividade de ensino de ciência, tecnologia e sociedade (CTS), na qual foram analisados rótulos de suplementos alimentares, com o objetivo norteador de auxiliar o professor na tarefa de avigorar ou renovar seus conhecimentos sobre temas químicos e suas relações com o trinômio química-saúde-sociedade. O trabalho foi desenvolvido com 74 alunos da terceira série do ensino médio, de uma escola pública do município de Mesquita, RJ. Foram observadas percepções discentes equivocadas acerca dos suplementos alimentares, que permitiram possibilidades de mediação entre o conhecimento escolar e o conhecimento do aluno, com novos significados para a química na vida dos alunos participantes da pesquisa. Abordar o tema suplementos alimentares em aulas de Química estabelece uma relação entre essa disciplina e a saúde, permitindo que os alunos reflitam sobre os riscos que envolvem o consumo de suplementos alimentares sem orientação profissional, além de um olhar crítico para o comércio dessas substâncias, com aspectos econômicos e éticos.

Palavras-chave: CTS. Química e saúde. Suplementos alimentares.

Professora de Química da rede estadual do Rio de Janeiro. Especialista em Musculação e Treinamento de Força. Atua como química na Universidade Federal do Rio de Janeiro, lotada no laboratório de Treinamento de Força. Mestranda em Ensino de Ciências no Programa de Pós-Graduação em Ensino de Ciências do Instituto Federal do Rio de Janeiro. E-mail: profmandacosta@gmail.com

* Professor do Instituto Federal do Rio de Janeiro - Campus Nilópolis, onde atua como professor formador no curso de licenciatura em Química e no quadro permanente do Programa de Pós-Graduação em Ensino de Ciências. E-mail: jorge.messeder@ifrj.edu.br 


\section{Introdução}

A educação em Química, ao contrário de outros campos da grande área da Química, não confere pesquisas com características quantitativas e por isso é pouco valorizada por seus pares. No entanto, trata-se da área que faz o elo entre o conhecimento científico e o conteúdo que deverá ser transmitido aos estudantes, fazendo com que a disciplina de Química se torne uma oportunidade para que o estudante compreenda o mundo fora da sala de aula. Essa compreensão permite que o aluno tenha condições de, em posse do conhecimento científico, tomar decisões relativas ao seu cotidiano de maneira consciente (CHASSOT, 2004).

Apesar de a escola ter como um de seus objetivos básicos "permitir que o aluno aprenda o conteúdo científico", diversos estudos sugerem que o distanciamento entre o conteúdo escolar e os alunos tem aumentado, fazendo com que a Química se torne uma disciplina difícil de ser entendida, limitada a conceitos, nomes e fórmulas, muitas vezes, sem sentido para o aluno (QUADROS, 1998; LIMA et al., 2000; GOMES; GOUVEIA, 2012). Compreender a Química torna-se de extrema importância quando nos damos conta que vivemos em um mundo repleto de compostos químicos e de reações químicas que ocorrem a todo momento. Apesar dos esforços de muitos professores, a escola não consegue despertar o interesse dos estudantes para estudar Química. Diante disso, a escola não tem realizado de maneira efetiva a alfabetização científica na área de Química (SANTOS, 2002).

Os princípios teóricos deste trabalho estão relacionados com os estudos de ciência, tecnologia e sociedade (CTS), uma vez que se buscou promover que os jovens participantes da atividade consolidassem a vocação pelos estudos da Química, em suas relações com a saúde humana, vislumbrando que a tecnologia deve ter grande importância social e não pode estar fora da atuação do professor em sua prática de sala de aula (BAZZO; LINSINGEN; PEREIRA, 2003). Ciente do fato de que a química permeia o cotidiano dos alunos, situações inerentes ao dia a dia dos estudantes geram excelentes oportunidades para uma aprendizagem significativa, que permite discussões sobre meio ambiente, saúde, ciência, tecnologia e sociedade (PINHEIRO; SILVEIRA; BAZZO, 2007). É necessário que o professor assuma o papel de mediador, mediando o conhecimento e permitindo que o aluno participe ativamente do processo de ensino e aprendizagem, percebendo também que a química acarreta implicações ambientais (KRASILCHIK; MARANDINO, 2007; DEMO, 2010). 
Para a condução da pesquisa, foi escolhida a abordagem sobre suplementos alimentares, que são produtos que possuem relação direta com a necessidade humana de se alimentar, necessidade esta que expressa a capacidade individual de fazer escolhas (MOHR, 2002). Dessa forma, torna-se importante a inserção dessa temática em aulas de ciências, uma vez que elas possibilitam sensibilizar os alunos sobre o conhecimento do próprio corpo e os assuntos relativos a esse conhecimento, exigindo tomada de decisão consciente em relação à manutenção da saúde. Muitos jovens têm buscado uma forma física mais atraente, sem considerar a segurança dos critérios adotados em tal busca, simplesmente seguindo o que a sociedade estabelece como "beleza estética", sem informações devidamente abalizadas (BELL et al., 2004; DAMASCENO et al., 2006).

A professora que conduziu a atividade é também atleta de fisiculturismo e possui perfis em redes sociais nos quais fala sobre suplementos alimentares, dentre outros temas relacionados ao esporte. Isso favorece que os alunos rotineiramente questionem a professora acerca desses produtos e relatem casos de uso ou de pessoas próximas que utilizam, corroborando a ideia de que suplementos alimentares são substâncias que permeiam o universo dos alunos. A atividade proposta permitiu que, além de identificar as substâncias químicas descritas nos rótulos dos produtos analisados, fosse realizada uma discussão em sala de aula sobre questões relacionadas a segurança química, saúde, ciência e tecnologia envolvendo a produção e a utilização desses produtos.

\section{Metodologia}

Para a realização da pesquisa, foi selecionada uma atividade demonstrativo-investigativa, desenvolvida de acordo com a definição de Silva, Machado e Tunes (2011, p. 241), em que o conceito de atividades experimentais utilizando espaços formais ou não formais e materiais que propiciem a interdisciplinaridade e a contextualização é ampliado pelos autores. Isso permite que o aluno estabeleça uma relação entre o fazer e o pensar no momento de aprender ciências. Na atividade demonstrativo-investigativa, o professor apresenta fenômenos simples para que, posteriormente, sejam introduzidos os conceitos teóricos.

A atividade foi desenvolvida no segundo semestre do ano letivo de 2018, durante as aulas de Química, com 74 alunos da terceira série do ensino médio, pertencentes 
a uma escola pública, situada no município de Mesquita (Baixada Fluminense, RJ). O objetivo foi permitir que os alunos validassem seus conhecimentos acerca dos suplementos alimentares - ou dessem um novo sentido a eles -, assim como a relação que esses produtos estabelecem com segurança alimentar, saúde, ciência e tecnologia. Para conduzir essa meta, os alunos deveriam identificar as substâncias químicas constituintes dos suplementos alimentares cujos rótulos foram analisados, esclarecer as funções dessas substâncias químicas, discutir sobre a indicação de uso dos suplementos alimentares pela população, o uso indiscriminado dos suplementos alimentares por pessoas que não têm indicação de profissionais da área de nutrição e a segurança relacionada à compra desses produtos em lojas sem a devida autorização para venda e, finalmente, identificar os efeitos para a saúde humana. Trata-se de um estudo de caráter qualitativo, exploratório e descritivo (MARCONI; LAKATOS, 2001).

A professora-pesquisadora leciona Química para os alunos que participaram da pesquisa, além disso, é atleta de fisiculturismo e mantém redes sociais nas quais discute sobre sua rotina de treinamento, sua alimentação e os suplementos alimentares contidos na sua dieta. Por ter uma forma física diferenciada, em consequência de sua prática esportiva, é constantemente questionada pelos alunos sobre o uso de suplementos alimentares, identificando a necessidade de esclarecer essa população sobre esse tema. A professora-pesquisadora também desenhou seus próprios objetivos profissionais com a atividade proposta, dentre eles: identificar algumas concepções prévias acerca da composição e do uso dos suplementos alimentares e de suas consequências para a saúde humana; adequar o tema a uma linguagem simples e de fácil compreensão pelo aluno; e encontrar estratégias didáticas para contextualizar o assunto "suplemento alimentar" e, assim, facilitar as relações de ensino e aprendizagem.

Foi solicitado que os alunos trouxessem rótulos de diversos suplementos alimentares, com diferentes objetivos nutricionais. Foram trazidos rótulos de termogênicos, hipercalóricos e suplementos proteicos para aumento de massa muscular. Os alunos foram divididos em grupos na sala de aula e receberam uma folha com uma tabela para o preenchimento com alguns dados do suplemento escolhido. Foi realizada uma conversa inicial motivadora, com foco no tema "Funções orgânicas" (hidrocarbonetos, funções oxigenadas, funções nitrogenadas e funções halogenadas), discutindo-se a composição química dos componentes descritos nos rótulos dos su- 
plementos alimentares analisados. Foram trabalhadas as funções álcool, cetona, aldeídos, éster, amina e ácido carboxílico. À medida que as curiosidades e dúvidas surgiam, a professora orientava os alunos, problematizando e discutindo com os grupos, observando os tópicos de ciência, tecnologia, segurança alimentar e saúde. Finalmente, ocorreu o preenchimento, com a participação de todos, de um quadro único, para pontuar possíveis semelhanças entre os suplementos analisados. Após o quadro estar devidamente preenchido, a professora explicou aos alunos algumas questões existentes acerca do tema.

\section{Resultados e discussões}

Durante a conversa motivadora, os alunos apresentaram suas concepções sobre os suplementos alimentares. De acordo com Boaventura de Sousa Santos (2002), todo conhecimento é autoconhecimento, com base nessa premissa é que se sugeriu que, a partir da produção dos alunos tanto em sala de aula como fora dela, é possível conhecer como esse aluno pensa a partir da análise do material produzido. É importante que, além da relevância dada aos aspectos relativos ao conhecimento no processo de abordagem das relações de ensino e aprendizagem, outros aspectos inerentes à constituição do aluno também sejam compreendidos, assim como os aspectos cognitivos (GOMES; DIONYSIO; MESSEDER, 2015). Perceber o aluno de forma ampla propicia que atividades educativas contribuam positivamente para a formação das suas identidades (GALIAZZI; MORAES, 2002).

Durante a conversa motivadora, ao serem questionados sobre quais substâncias faziam parte da composição dos suplementos alimentares, os alunos citaram com mais propriedade a proteína. Porém, não souberam estabelecer relação entre a proteína existente nos suplementos e nos alimentos e os aspectos bioquímicos da alimentação humana. Ao serem questionados sobre a composição dos outros suplementos citados, como: whey protein (nome comercial que foi dado à proteína feita a partir do soro do leite, extraída durante o processo de transformação do leite em queijo), cretina, BCAA (branch chain amino acids), que significa aminoácidos de cadeia ramificada, e termogênicos, os alunos não souberam descrever o que eles consideram fazer parte da composição dessas substâncias, limitando-se apenas a dizer a finalidade do uso dos produtos, tais como aumento de massa muscular e emagrecimento. Os alunos participantes demonstraram não perceber os suplemen- 
tos alimentares como sendo parte da complementação alimentar, mas como sendo produtos que melhoram a forma física ou o desempenho de maneira diferente da "comida de verdade". Alguns alunos demonstraram atribuir uma superioridade do suplemento alimentar quando comparado à comida, entendendo ser "melhor" consumir suplemento do que se alimentar de forma clássica.

No segundo encontro, ao analisarem os rótulos dos suplementos alimentares, os alunos preencheram um quadro no qual relacionaram o que havia em comum na composição química desses produtos. Os alunos pontuaram proteína, carboidrato e gorduras saturadas como sendo as estruturas presentes em whey protein, BCAA e creatina (Quadro 1). Eles destacaram também que, no rótulo de todos os suplementos analisados, havia presença de vitaminas. Ao verificar o rótulo dos termogênicos, os alunos perceberam a presença de cafeína. Após o preenchimento do quadro, puderam perceber que, apesar da variação da quantidade, os suplementos apresentam alguns componentes em comum em suas fórmulas. A professora trouxe então a informação da importância da orientação profissional no momento da escolha do suplemento adequado. O levantamento bibliográfico realizado por Becker et al. (2016) indica a importância da prescrição de suplementação alimentar, não só para atletas, mas para todos que fazem uso dessas substâncias.

Quadro 1 - Componentes presentes nos suplementos analisados pelos alunos

\begin{tabular}{|c|c|c|}
\hline Whey protein & BCAA & Creatina \\
\hline Carboidratos & Carboidratos & Carboidratos \\
\hline Proteínas & Proteínas & Proteínas \\
\hline Vitaminas & Vitaminas & Vitaminas \\
\hline Gorduras saturadas & Gorduras saturadas & Gorduras saturadas \\
\hline
\end{tabular}

Fonte: elaboração dos autores.

Outro ponto de destaque foi a relação estabelecida entre a composição dos suplementos e a da "comida de verdade". A professora citou exemplos de alimentos que são compostos por proteína, carboidratos e gorduras, tais como leite e castanhas, porém, em quantidades diferentes. Os alunos se mostraram surpresos ao perceberem que os constituintes presentes na composição dos suplementos, são os mesmos que constituem os alimentos. A professora esclareceu, então, o papel dos suplementos alimentares como produtos que têm o objetivo de complementar o déficit nutricional 
que a alimentação não supra por algum motivo, sendo desnecessário o consumo desse tipo de produto por indivíduos que não tenham necessidades nutricionais específicas. A partir do desdobramento dessa discussão, a professora trouxe para os alunos a reflexão sobre a diferença de preços entre a "comida de verdade" e os suplementos alimentares que apresentam elevado valor comercial. Foi possível estabelecer uma relação entre o poder da mídia e o valor comercial agregado à expectativa do que o consumo de suplementos alimentares pode gerar no indivíduo.

\section{Considerações finais}

Sair do papel de simples transmissor de conhecimento químico e buscar maneiras de contextualizar o conteúdo abordado em sala de aula com temas que permeiem a realidade do aluno é uma maneira de o professor imprimir significado ao conteúdo transmitido, favorecendo os processos de ensino e aprendizagem. Torna-se relevante que o professor promova atividades que propiciem o debate de temas que não estejam presentes no currículo. $\mathrm{O}$ assunto suplementos alimentares não é tratado na temática do ensino médio, no entanto, é fundamental que o professor reflita sobre a realidade da escola e busque relacionar a química com o cotidiano dos alunos.

Os conteúdos programáticos contidos no currículo de Química destinado para o ensino médio demandam tempo para serem abordados pelo professor, e qualquer assunto que não esteja inserido nesse planejamento pode comprometer o cronograma. Contudo, já existem autores que destacam a magnitude da importância de abordar temas de CTS associados aos conteúdos de Química em sala de aula (MORTIMER; MACHADO, 2002; SANTOS; MÓL, 2010; LISBOA, 2011). A abordagem de CTS possibilita que o aluno relacione a química ao seu cotidiano, favorecendo a tomada de decisão consciente. As atividades desenvolvidas nas aulas de Química mostraram-se consonantes com muitas experiências que têm sido divulgadas com o enfoque de CTS no ensino médio, podendo ser classificadas como um enxerto CTS, que, de acordo com Sanmartín, e Luján (1992), se caracteriza como a introdução de CTS nos conteúdos das disciplinas de ciências.

Abordar o tema suplementos alimentares dentro do contexto da Química estabelece uma relação entre essa disciplina e saúde, permitindo que os alunos reflitam sobre os riscos que envolvem o consumo de suplementos alimentares sem orientação profissional. Outra relação estabelecida a partir dessa temática é entre química 
e sociedade, a qual possibilita que o aluno reconheça as estratégias de marketing existentes em torno do consumo de suplementos alimentares, fazendo escolhas com um novo olhar, mais amplo e crítico, considerando os aspectos econômicos e éticos que permeiam o comércio dessas substâncias.

\section{Analysis of food supplement labels in Chemistry classes: a STS teaching activity}

\section{Abstract}

This work presents a STS teaching activity, where food supplement labels were analyzed, with the aim of assisting the teacher in the task of invigorating or renewing his knowledge about chemical topics and their relationship with the Chemical-Health-Society trinomial. The work was developed with 74 students of the third grade of high school, of a public school in the municipality of Mesquita (RJ). Wrong student perceptions about dietary supplements were observed, which allowed possibilities of mediation between school knowledge and student knowledge, with new meanings to Chemistry in the life of the students participating in the research. Addressing the topic of food supplements in chemistry classes, establishes a relationship between Chemistry and Health, and allows students to reflect on the risks involved in the consumption of dietary supplements without professional guidance, in addition to a critical look at the trade of these substances, with economic and ethical aspects.

Keywords: CTS. Chemistry and health. Dietary supplements.

\section{Referências}

BAZZO, W. A.; LINSINGEN, I. V.; PEREIRA, L. T. V. Introdução aos estudos CTS (Ciência, Tecnologia e Sociedade). Madri: Organização dos Estados Ibero-americanos, 2003.

BECKER, L. K. et al. Efeitos da suplementação nutricional sobre a composição corporal e o desempenho de atletas: uma revisão. Revista Brasileira de Nutrição Esportiva, São Paulo, v. 10, n. 55, p. 93-111, jan./fev. 2016. Disponível em: http://www.rbne.com.br/index.php/rbne/article/ download/549/531. Acesso em: 13 out. 2018.

BELL, A. et al. A look at nutritional supplement use in adolescents. Journal Adolescent Health, San Francisco, v. 34, p. 508-516, 2004.

CHASSOT, A. Para que(m) é útil o ensino? 2. ed. Canoas: Editora Ulbra, 2004.

DAMASCENO, V. O. et al. Imagem corporal e corpo ideal. Revista Brasileira Ciência e Movimento, Brasília, DF, v. 14, n. 2, p. 81-94, 2006.

DEMO, P. Educação e Alfabetização Científica. São Paulo: Papirus, 2010.

GALIAZZI, M. C.; MORAES, R. Educação pela pesquisa como modo, tempo e espaço de qualificação da formação de professores de Ciências. Ciência \& Educação, Bauru, v. 8, n. 2, p. 237-252, 2002. 
GOMES, L. M. J. B.; GOUVEIA, D. S. M. Há Química no meio do caminho, no meio do caminho há Química. In: SIMPÓSIO DE PROFISSIONAIS DO ENSINO DE QUÍMICA. Comunicação oral. Campinas: Editora da Unicamp, 2012. Disponível em: http://gpquae.iqm.unicamp.br/lisTrabalhosSIMPEQ11.pdf. Acesso em: 13 out. 2018.

GOMES, L. M. J. B.; DIONYSIO, L. J. M.; MESSEDER, J. C. Análise de rótulos de produtos domissanitários como forma de discutir a Química no cotidiano dos estudantes. Educación Química, Universidad Nacional Autónoma de México, v. 26, n. 1, p. 21-25, 2015.

KRASILCHIK, M.; MARANDINO, M. Ensino de ciências e cidadania. 2. ed. São Paulo: Moderna, 2007.

LIMA, F. L. L. et al. Contextualização no ensino de cinética química. Química Nova na Escola, São Paulo, v. 11, p. 26-29, 2000.

LISBOA, J. C. F. (org.). Química. São Paulo: SM, 2011. (Coleção Ser Protagonista, v. 1, 2 e 3 ).

MARCONI, M. A.; LAKATOS, E. M. Metodologia do trabalho científico. 6. ed. São Paulo: Atlas, 2001.

MOHR, A. A natureza da educação e saúde no ensino fundamental e os professores de ciências. 2002. 252 f. Tese (Doutorado em Educação) - Universidade Federal de Santa Catarina, Florianópolis, 2002. Disponível em: http://repositorio.ufsc.br/xmlui/handle/123456789/83375. Acesso em: 13 out. 2018.

MORTIMER, E. F.; MACHADO, A. H. Química para o ensino médio. São Paulo: Scipione, 2002.

PINHEIRO, N. A. M.; SILVEIRA, R. M. C. F.; BAZZO, W. A. Ciência, tecnologia e sociedade: a relevância do enfoque CTS para o contexto do ensino médio. Ciência \& Educação, Bauru, v. 13, p. 71-84, 2007.

QUADROS, A. L. Feromônios. Química Nova na Escola, São Paulo, v. 7, p. 7-10, 1998.

SANMARTÍN, J.; LUJÁN, J. L. Educación en ciencia, tecnología y sociedad: estudios sobre sociedad y tecnología. Barcelona: Antthropos, 1992.

SANTOS, B. S. Um discurso sobre as ciências. 13. ed. Porto: Afrontamento, 2002.

SANTOS, W. L. P.; MÓL, G. S. (coord.). Química cidadã. São Paulo: Nova Geração, 2010. v. 1.

SILVA, R. R.; MACHADO, P. F. L.; TUNES, E. Experimentar sem medo de errar. In: SANTOS, W. L. P.; MALDANER, O. A. (org.). Ensino de Química em Foco. Ijuí: Editora Unijuí, 2011. p. 231-261. 